\title{
A comparative clinical study on efficacy of nanofilled resin-modified and conventional glass ionomer pit and fissure sealant in molar tooth
}

\author{
Dilruba Khatun, Mozammal Hossain, Md. Joynal Abdin, Md. Abdul Hannan Sheikh and \\ Md. Shamsul Alam
}

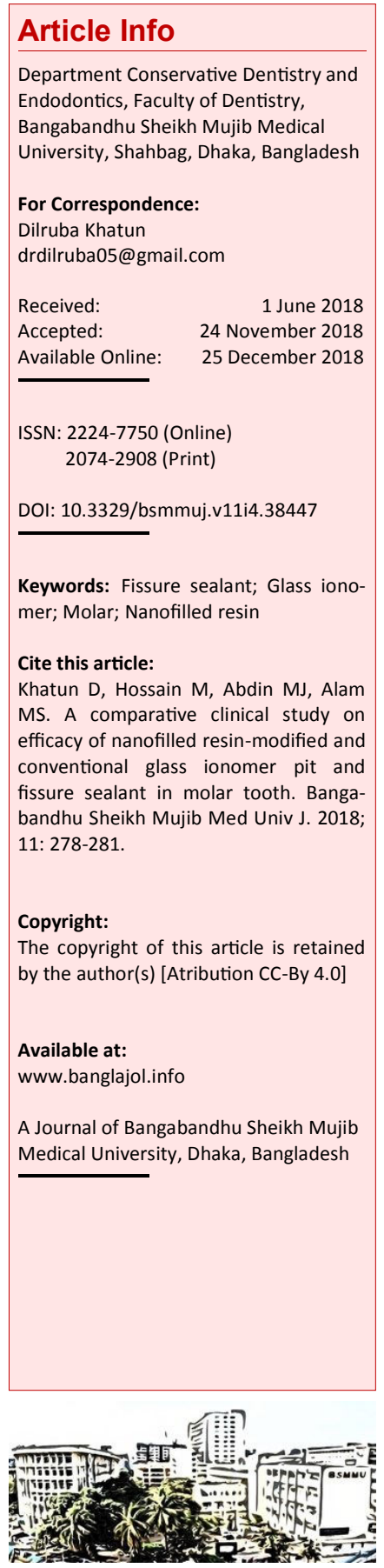

\section{Abstract}

The clinical performances of nanofilled resin-modified glass ionomer and conventional glass ionomer pit and fissure sealant were compared on permanent molar. Patient having bilateral occlusal grooves in pit and fissure of the occlusal surface were included for this study where 50 were treated with nanofilled resin-modified and the remaining 50 were subjected to conventional glass ionomer sealant. The color match, retention and marginal adaptation were assessed at 3, 6 and 12 months. The results showed that nanofilled resin-modified glass ionomer sealant showed better color stability, more retention, and better marginal adaptation at 12 months. The results suggested that nanofilled resin-modified glass ionomer sealant exhibited better clinical performance than that of conventional glass ionomer sealant at 12 months observation period.

\section{Introduction}

Pit and fissure of the human molar tooth are considered as caries prone dental sites. Furthermore, inadequate post-eruptive maturation and complex morphology help in the accumulation of plaque which also favor the development of carious lesion in pit and fissure.1-2 A study on children showed that $22 \%, 50 \%$ and $75 \%$ have experienced decay in their permanent teeth at 8 , 12 and 15 year of age, respectively. 3 Another study indicated that a total of $10.7 \%$ of the US children and $14 \%$ of children aged 6 to 12 years experienced tooth decay and toothache in a 6 months survey. $\underline{4}$ Therefore, the susceptibility of pit and fissure has encouraged researchers to find ways to prevent this situation. $\frac{5}{-}$

Application of pit and fissure sealants such as resin-based and glass ionomer sealants is considered as an effective method to decrease dental caries as they create a thin barrier on the pit and fissure and protects the surface from caries initiation. 6 Conventional glass ionomer was used as a sealant of pit and fissure of erupted permanent molar tooth. -9 It is biocompatible with the pulpal tissue, and it has the ability to chemically bond to the tooth tissue and it has almost similar co-efficient of thermal expansion to that of tooth structure and ability to fluoride release. $\underline{10}$ However, its low physical and mechanical strength, moisture sensitivity during the initial setting time, poor wear resistance, loss of anatomic form or marginal adaptation limit their use in load bearing areas. 11 On the other hand, resin-based sealant which is composed of acrylic (methacrylate) monomer associated with filler or fluoride, and is considered to have better clinical performance than that of conventional glass ionomer cement.12 Low-viscosity flowable composites could also be used as fissure sealant. $\underline{13-14}$

Recently, nanoparticulated resin-modified glass ionomer has been developed which contain nanofiller particles of 0.1 to 100 nanometer. Ketac Nano $100^{\mathrm{TM}}$, a nanofilled resin-modified glass ionomer cement is now commercially available which is said having better adhesion, polishing ability and aesthetics. $\underline{15}$ Furthermore, abrasion resistance and fluoride release have been increased. $\underline{16}$ In addition, they have minimum voids, cracks and microporosities on the surfaces of nanofilled resin-modified glass ionomer than the conventional ionomers. $\underline{17}$ Therefore, nanofilled resin-modified glass ionomer (Ketac Nano 100 100 ) is considered as a reliable alternative to other conventional glass ionomer (Fuji IX) as a pit and fissure sealant. The aim of this study was to compare the clinical efficacy of two glass ionomers (Ketac Nano $100^{\mathrm{TM}}$ and Fuji IX) in sealing pit and fissure in vivo.

\section{Materials and Methods \\ Fifty participants (age range: 10-15 years) having two deep occlusal grooves in each case in fully erupted permanent molar teeth were}


Table I

\begin{tabular}{|l|c|rrr|}
\hline \multirow{5}{*}{$\begin{array}{c}\text { Comparison of clinical outcome at } 12 \text { months } \\
\text { Evaluation criteria }\end{array}$} & \multicolumn{4}{c|}{ Groups } \\
\cline { 2 - 5 } & Score & $\begin{array}{c}\text { Ketac }^{\mathrm{TM}} \text { Nano } 100 \\
(\mathrm{n}=50)\end{array}$ & $\begin{array}{c}\text { Fuji IX } \\
(\mathrm{n}=50)\end{array}$ & p value \\
\hline Color match & Alpha & 48 & 41 & \\
& Bravo & 2 & 4 & 0.045 \\
& Charlie & 0 & 5 & \\
Retention & Alpha & 48 & 40 & \\
& Bravo & 2 & 7 & 0.039 \\
& Charlie & 0 & 3 & \\
Marginal adaptation & Alpha & 48 & 40 & \\
& Bravo & 1 & 6 & 0.047 \\
& Charlie & 1 & 4 & \\
\hline
\end{tabular}

used in this study. The occlusal surface of 50 teeth was sealed with Ketac Nano 100TM (3M, ESPE, USA) and the remaining 50 teeth were subjected to Fuji IX (GC, Japan).

\section{Procedure for Katac ${ }^{T M}$ Nano 100}

At first, pit and fissure area were cleaned by using a slurry of pumice and a bristle brush and dried. The primer was applied for $30 \mathrm{sec}$ and gently dried for $30 \mathrm{sec}$ and then light cured for another $10 \mathrm{sec}$. The sealant material was inserted into the prepared surface with an applicator to avoid entrapping air and light activated for $15 \mathrm{sec}$. The final restoration was polished by using conventional finishing and polishing instruments. Finally, the occlusion was checked with articulating paper and adjustment was made in order to avoid any premature contact.

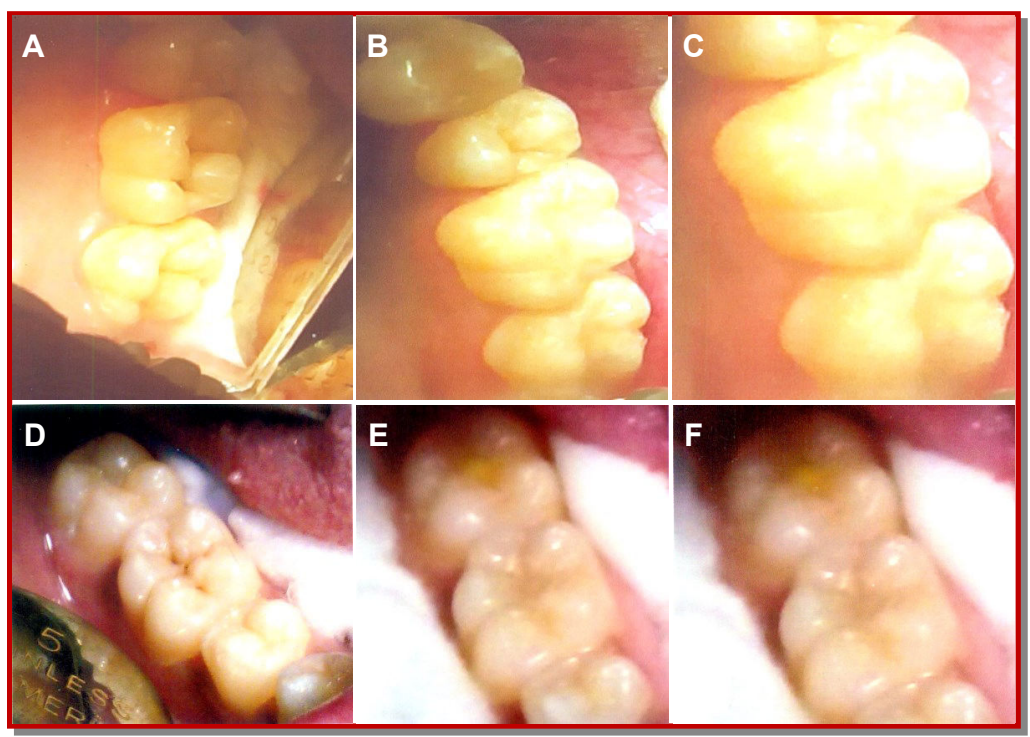

Figure 1: (Upper row) Representative clinical photographs of Ketac nano 100 restorations at preoperative (A), post-operative (B) and at 12 months (C) observation period; (Lower row) Representative clinical photographs of Fuji IX restoration at preoperative (D), post-operative (E) and at 12 months (F) observation period

\section{Procedure for Fuji IX}

Following cleaning with a slurry of pumice and a bristle brush, the surface was prepared with conditioner for $30 \mathrm{sec}$, rinsed and air-dried. Prepared sites were sealed with Fuji IX conventional glass ionomer cement. After sealing, the occlusion was checked with articulating paper and adjusted to avoid overload.

\section{Follow-up}

The participants were recalled for clinical evaluations at 3 and 6 months interval for the assessment of retention, marginal adaptation and color matching. The retention was rated as Alpha: Complete retention, Bravo: Partial retention and Charlie: Complete loss. The color was rated as Alpha: Color matches with the adjacent tooth; Bravo: Light mismatch and Charlie: Mismatch. The marginal adaptation was rated as Alpha: No visual evidence of a crevice, Bravo: Visible crevice and explorer penetrate or catch and Charlie: The restoration is fractured, mobile or missing.

The collected data was analyzed using Statistical Package for Social Science (SPSS) version 19. Chisquare test was applied to assess the difference between the clinical outcome of Ketac ${ }^{\mathrm{TM}}$ Nano 100 and Fuji IX. A value of $p<0.05$ was considered as statistical significant.

\section{Results}

The results of clinical outcome are shown in Table I. Figure 1 represents the clinical photographs of Ketac nano 100 and Fuji IX restorations at preoperative (A), postoperative (B) and at 12 months (C). It was found that the color stability of Ketac ${ }^{\mathrm{TM}}$ Nano 100 restoration retained alpha rating at baseline, 3 and 6 months, and then gradually decreased at 12 months. At 12 months, 2 (4\%) Ketac TM Nano 100-treated teeth showed Bravo rating. The remaining $48(96 \%)$ restorations keep their color stable during this period. On the other hand, 5 $(10 \%)$ Fuji IX sealant restoration showed Bravo rating at 6 months, followed by $4(8 \%)$ Bravo and 5 $(10 \%)$ Charlie rating at 12 months. The remaining 41 (82\%) Fuji IX also kept their color stable at 12 months.

On sealant retention, it was found that 1 (2\%) Ketac $^{\mathrm{TM}}$ Nano 100 and 6 (12\%) Fuji IX sealant restorations showed Bravo rating at 6 months. However, at 12 months, 2 (4\%) Ketac ${ }^{\mathrm{TM}}$ Nano 100 showed Bravo rating. On the other hand, 7 (14\%) Fuji IX showed Bravo and $3(6 \%)$ showed Charlie (complete loss) rating. The differences between Ketac $^{\mathrm{TM}}$ Nano 100 and Fuji IX in respect to retention were statistically significant at 12 months. Furthermore, the results of marginal adaptation showed that marginal adaptation could be achieved with 


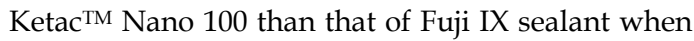
examined with explorer and mirror. At 6 months, 1 (2\%) Ketac ${ }^{\mathrm{TM}}$ Nano 100 and 7 (14\%) Fuji IX revealed Bravo rating. However, at 12 months, 1 (2\%) Ketac $^{\mathrm{TM}}$ Nano 100 showed bravo rating and one (2\%) revealed Charlie rating. On the other hand, 6 (12\%) Fuji IX showed Bravo and 4 (8\%) revealed Charlie rating at 6 and 12 months, respectively. The result between the two sealants at 6 and 12 months in respect to color stability, retention and adaptation were statistically significant $(\mathrm{p}<0.05)$.

\section{Discussion}

It was confirmed that nanofilled sealants (Ketac ${ }^{\mathrm{TM}}$ Nano 100) showed better clinical performance than that of conventional glass ionomer sealants. The retention and marginal adaptation were acceptable and the color was stable with the same tooth structure. The results corresponded to a previous study that Ketac ${ }^{\mathrm{TM}}$ Nano 100 exhibited better clinical outcome than that of conventional glass ionomer cement. $\underline{17}$

Previous studies have indicated that the clinical success of sealant is related to the retention, marginal adaptation and color stability. $\underline{.18-19}$ The color stability of Ketac nano was better than that of Fuji IX is corresponded to a previous study that the color stability of Ketac ${ }^{\mathrm{TM}}$ Nano 100 was better than the Fuji IX glass ionomer cement. 20 The reason for the difference better color stability in Ketac ${ }^{\mathrm{TM}} \mathrm{Nano}$ 100 may be due to the differences in the size of glass particles used in Fuji IX and Ketac ${ }^{\mathrm{TM}}$ Nano 100. In the case of Fuji IX, the size of filler ranged between $7,130 \mathrm{~nm}$ to $13,430 \mathrm{~nm}$, which is larger than the wavelength of light $(350-750 \mathrm{~nm})$. These particles may also scatter blue light and produces opaque. 21 22 In the case of Ketac ${ }^{\mathrm{TM}}$ Nano 100, the particle size of 0.1 to $100 \mathrm{~nm}$ is far below than that of the wavelength of light. Therefore, light can passes directly through the materials and results in makes in translucent. It also scatters blue light giving the restoration an opaque effect. $\underline{23}$ Furthermore, few void or microporosities was detected on the surface of Nano ionomer than the other ionomer cement, which might increase the color stability.24 However, a number of restorations were failed to retain the color stability. It may be due to differences in the filler size or discoloration of the monomer of Ketac $^{\mathrm{TM}}$ Nano 100.20 On the other hand, loss of color stability in Fuji IX may be due to either chemical reaction of the resin matrix or water absorption and loss of surface characteristics. $\underline{20}$

On sealant retention, some restorations were partially or completely lost after a period of time in both groups. Restorations which were partially lost were replaced with respective material. There are several reasons need to be considered for the loss of retention in both Ketac ${ }^{\mathrm{TM}}$ Nano 100 and Fuji IX. The retention loss may occur due to moisture contamination, secondary loss of the material under occlusal force, inadequate adhesion and less penetration of the sealant into the cavity. .5 The residual debris or entrapped air may also be responsible for the loss of retention. 17 Therefore, insufficient removal of debris from the fissure could inhibit the penetration of sealant into the enamel surface. This is also supported by some of the previous studies that adequate cleaning of pit and fissure is essential for the success of fissure sealant retention. 18 It may be the possible reason for higher loss of retention in Fuji IX restoration at 12 months.

A number of restorations in both groups partially lost their marginal adaptation and they were due to marginal chipping of enamel. There are several reasons of chipping of enamel surface that includes direct contact of the restoration with the opposite tooth cusp and thinning of the enamel surface. Another possible reason for adaptation loss might be due to the flow of materials. Furthermore, one previous study has reported that the loss of marginal adaptation of Fuji IX might be the marginal deficient or moisture contamination at the early period.26 In the case of Ketac ${ }^{\mathrm{TM}}$ Nano 100, the flow could resist by the instant resin polymerization, and once the set, they are protected from the moisture contamination and showed better marginal adaptation. The other reason could be the use of KetacTM Nano primer that might enhance the adhesion, water uptake and expansion of the cement. $\underline{6}$ However, one previous study also reported that the loss of marginal adaptation may also develop due to entrapped air or voids during filling of the cavity. 18

\section{Conclusion}

Nanofilled resin-modified glass ionomer Ketac $^{\mathrm{TM}}$ Nano 100) is superior to the conventional glass ionomer sealant (Fuji IX) in respect to color stability, retention and marginal adaptation.

\section{References}

1. Cvikl B, Moritz A, Bekes K. Pit and fissure sealantsA comparative review. Dent J (Basel). 2018; 6: 18.

2. Sreedevi A, Mohammed S. Sealants, pit and fissure. Stat Pearls [Internet]. USA, Stat Pearls Publishing, 2018 (in press).

3. Whelton $\mathrm{H}$, Fox C. Advances in the prevention of oral disease: The role of the international association for dental research. BMC Oral Health. 2015; 15: 8.

4. Lewis C, Stout J. Toothache in US children. Arch Pediatr Adolesc Med. 2010; 164: 1059-63. 
5. Ganesh M, Shobha T. Comparative evaluation of the marginal ability of Fuji VII and concise as pit and fissure sealant. J Contemp Dent Practise. 2007; 8: 10-18.

6. Al-Jobair A, Al-Hammad N, Alsadhan S, Salama F. Retention and caries-preventive effect of glass ionomer and resin-based sealants: An 18-monthrandomized clinical trial. Dent Mater J. 2017; 36: 654-61.

7. Hubel S, Mejare I. Conventional versus resinmodified glass-ionomer cement for class II restoration in primary molars. A 3-years clinical study. Int J Paediatr Dent. 2003; 13: 2-8.

8. Yilmaz Y, Eyuboglu O, Kocogullari ME, Belduz N. A one-year clinical evaluation of high-viscosity glass ionomer cement in primary molars. J Contemp Dent Pact. 2006; 7: 71-78.

9. Malek S, Hossain M, Gafur MA, Rana MS, Moral MAA. Comparative study of resin sealant and resin modified glass ionomer as pit and fissure sealant. Bangabandhu Sheikh Mujib Med Univ J. 2017; 10: 21-26.

10. Maldonado A, Swartz ML, Phillips RW. An in vitro study of certain properties of a glass ionomer cement. J Am Dent Assoc. 1978; 96: 785-91.

11. Koupis NS, Marks LA, Verbeeck RM, Martens LC. Finishing and polishing procedures of (resinmodified) glass ionomers and compomers in paediatric dentistry. Eur Arch Paediatr Dent. 2007; 8: 22-28.

12. Ei TZ, Shimada Y, Nakashima S, Romero MJRH, Sumi Y, Tagami J. Comparison of resin-based and glass ionomer sealants with regard to fluoriderelease and anti-demineralization efficacy on adjacent unsealed enamel. Dent Mater. 2018; 30: 104 -12 .

13. Dias KR, de Andrade CB, Wait TT, Chamon R, Ammari MM, Soviero VM, Lobo L, de Almeida Neves A, Maia LC, Fonseca-Gonçalves A. Efficacy of sealing occlusal caries with a flowable composite in primary molars: A 2-year randomized controlled clinical trial. J Dent. 2018; 74: 49-55.

14. Kucukyilmaz E, Savas S. Evaluation of different fissure sealant materials and flowable composites used as pit-and-fissure sealants: A 24-month clinical trial. Pediatr Dent. 2015; 37: 468-73.

15. Pedroso LB, Barreto LF, Miotti LL, Nicoloso GF, Durand LB. Effect of a surface sealant on the color stability of composite resins after immersion in staining solution. Gen Dent. 2016; 64: 22-25.

16. Zakaria MA, Hossain M, Moral MAA. Comparative efficacy of nanofilled and microfilled resin modified glass ionomer as pits and fissure sealant in permanent molar tooth. Bangabandhu Sheikh Mujib Med Univ J. 2017; 10: 53-57.

17. Psachoal MA, Magalhaes AC, Rios D, Abdo RC, Gurgel CV, Chaves JV, et al. Fluoride release of a nanoparticulated resin modified glass ionomer cement. Oral health and preventive dentistry. $86^{\text {th }}$ General session and exhibition of the IADR 2008. Toronto, Annals IADR, 2008, pp 61-65.

18. Duangthip D, Lussi A. Effects of application techniques and fissure types on the in vitro performance of two fissure sealants. Am J Dent. 2004; 17: 137-42.

19. Kühnisch J, Mansmann U, Heinrich-Weltzien R, Hickel R. Longevity of materials for pit and fissure sealing: Results from a meta-analysis. Dent Mater. 2012; 28: 298-303.

20. Konde S, Raj S, Jaiswal D. Clinical evaluation of a new art material: Nanoparticulated resin-modified glass ionomer cement. J Int Soc Prev Community Dent. 2012; 2: 42-47.

21. Wang XY. Effect of early water exposure on the strength of glass ionomer restoratives. Oper Dent. 2006; 31: 584-89.

22. Onal B, Pamir T. The two-year clinical performance of esthetic lesions restorative materials in noncarious cervical. J Am Dent Assoc. 2005; 136; 1547-55.

23. Mitra SB, Wu D, Holmes BN. An application of nanotechnology in advanced dental materials. J Am Dent Assoc. 2003; 134: 1382-90.

24. Vance M, Lawson NC, Rupal M, Beck P, Burgess JO. Color and gloss of nano-filled resin-modified glass ionomers and resin composites. J Esthet Restor Dent. 2015; 27: 293-99.

25. Messer LB, Calache H, Morgan MV. The retention of pit and fissure sealants placed in primary school children by Dental Health Services, Victoria. Aust Dent J. 1997; 42: 233-39.

26. Van Dijken JW, Horstedt P. Marginal adaptation of a polyacid-modified resin composite (compomer) and a resin-modified glass ionomer cement in vivo. Clin Oral Invest. 1997; 1: 185-90. 